\title{
Identification of potential cervical cancer serum biomarkers in Thai patients
}

\author{
SIRIPORN KEERATICHAMROEN $^{1 *}$, PANTIPA SUBHASITANONT $^{1 *}$, DARANEE CHOKCHAICHAMNANKIT $^{1}$, \\ CHURAT WEERAPHAN $^{1,2}$, KITTIRAT SAHARAT ${ }^{1}$, NARONGRIT SRITANA ${ }^{3}$, NUTTAVUT KANTATHAVORN ${ }^{4}$, \\ KRIANGPOL WIRIYAUKARADECHA ${ }^{3}$, THANIYA SRICHARUNRAT ${ }^{5}$, N. MONIQUE PARICHARTTANAKUL ${ }^{1}$, \\ CHIRAYU AUEWARAKUL ${ }^{6,7}$, JISNUSON SVASTI ${ }^{1,8}$ and CHANTRAGAN SRISOMSAP ${ }^{1}$
}

${ }^{1}$ Laboratory of Biochemistry, Chulabhorn Research Institute, Bangkok 10210; ${ }^{2}$ Department of Molecular Biotechnology and Bioinformatics, Faculty of Science, Prince of Songkla University, Songkhla, Songkhla 90110; ${ }^{3}$ Molecular and Genomic Research Laboratory, Research and International Relations Division, HRH Princess Chulabhorn College of Medical Science;

${ }^{4}$ Gynecologic Oncology Unit, Women's Health Center and ${ }^{5}$ Pathology Laboratory Unit, Chulabhorn Hospital;

${ }^{6}$ Research and International Relations Division, HRH Princess Chulabhorn College of Medical Science,

Chulabhorn Royal Academy, Bangkok 10210; ${ }^{7}$ Department of Medicine, Faculty of Medicine,

Siriraj Hospital, Mahidol University, Bangkok 10700; ${ }^{8}$ Applied Biological Sciences Program,

Chulabhorn Graduate Institute, Bangkok 10210, Thailand

Received April 23, 2019; Accepted February 4, 2020

DOI: $10.3892 / \mathrm{ol} .2020 .11519$

\begin{abstract}
Cervical cancer is one of the most common causes of cancer-associated mortality in females worldwide. Serum biomarkers are important tools for diagnosis, disease staging, monitoring treatment and detecting recurrence in different types of cancer. However, only a small number of established biomarkers have been used for clinical diagnosis of cervical cancer. Therefore, the identification of minimally invasive, sensitive and highly specific biomarkers for detection of cervical cancer may improve outcomes. In the present pilot study, changes in disease-relevant proteins in 31 patients with cervical cancer were compared with 16 healthy controls. The Human 14 Multiple Affinity Removal system was used to deplete the 14 most abundant serum proteins to decrease sample complexity and toenrich proteins that exhibited decreased levels of abundance in the serum samples. Immunoaffinity-depleted serum samples were analyzed by in-gel digestion, followed by liquid chromatography mass spectrometry analysis and data processing. Automated quantitative western blot assays and receiver operating characteristic (ROC) curves were used to
\end{abstract}

Correspondence to: Dr Chantragan Srisomsap, Laboratory of Biochemistry, Chulabhorn Research Institute, 54 Kamphaeng Phet 6, Talat Bang Khen, Bangkok 10210, Thailand

E-mail: chantragan@cri.or.th

${ }^{*}$ Contributed equally

Key words: serum biomarkers, cervical cancer, Human 14 Multiple Affinity Removal System, $\alpha$-1-antitrypsin, pyrroline-5-carboxylate reductase 2, transthyretin, apolipoprotein A-I, vitamin D binding protein, multimerin-1 evaluate the differential protein expression levels between the two groups. Capillary electrophoresis-based western blot analysis was performed to quantitatively determine serum levels of the candidate biomarkers. Significantly increased levels of $\alpha$-1-antitrypsin (A1AT) and pyrroline-5-carboxylate reductase 2 (PYCR2) were detected, whereas the levels of transthyretin (TTR), apolipoprotein A-I (ApoA-I), vitamin D binding protein (VDBP) and multimerin-1 (MMRN1) were significantly decreased in patients with cervical cancer compared with the healthy controls. ROC curve analysis indicated that the sensitivity and specificity was improved through the combination of the 6 candidate biomarkers. In summary, the results demonstrated that 6 candidate biomarkers (A1AT, PYCR2, TTR, ApoA-I, VDBP and MMRN1) exhibited significantly different expression between serum samples from healthy controls and patients with cervical cancer. These proteins may represent potential biomarkers for distinguishing patients with cervical cancer from healthy controls and for differentiation of patient subgroups.

\section{Introduction}

Carcinoma of the cervix remains a common cause of cancer-associated mortality in women in developing countries, including Thailand. Almost all cases of cervical cancer are caused by persistent infection with the high-risk (oncogenic type) human papilloma virus (HPV), where types 16 and 18 are responsible for $75 \%$ of cervical cancer cases, and types 31 and 45 are responsible for $10 \%$ of cases (1). Generally, the majority of women with the early-stages of cervical cancer are asymptomatic, and patients become aware of symptoms when the disease has advanced. Therefore, preventative measures, including vaccination against HPVs and early detection of abnormal cytological changes through screening tests are 
recommended. In developed countries, widespread use of the typical screening procedure, the Papanicolaou (Pap) smear, enables early detection of cervical cancer, and thereby has markedly decreased the incidence and mortality rates of cervical cancer where these tests are frequently adopted (2). However, the disadvantages of the Pap test and other screening programs, such as visual inspection with acetic acid, HPV DNA testing and liquid-based cytology include discomfort, the invasive and sensitive nature of the tests, and low levels of sensitivity and specificity (3). Therefore, developing a simpler, less invasive and more accurate method for cervical cancer diagnosis may further improve early detection rates.

Serum is an attractive biomaterial for diagnosis due to the minimally invasive means of sample collection. However, a significant drawback of analyzing serum proteins is the dynamic concentration range of different proteins in serum samples. The 10 most abundant serum proteins constitute $>85 \%$ of total serum proteins, whereas the proteins of interest are likely present at extremely low concentrations. A variety of high-abundant protein depletion methods have been reported, for example, affinity purification, organic precipitation, solid phase extraction and immunodepletion. In the present study, the Human 14 Multiple Affinity Removal System (MARS-14) immunoaffinity column was used to remove the 14 most abundant serum proteins. Depletion of these highly abundant proteins allows for improved detection of the potential pathogenic factors and biomarkers.

Serum biomarkers are valuable tools for non-invasive diagnosis, disease staging, prognosis, prediction of therapy response and detection of disease recurrence. Elevated levels of various serum biomarkers, including cancer antigen (CA)15-3, CA19-9, CA125, serum fragments of cytokeratin (CYFRA 21-1), carcinoma embryonic antigen, squamous cell carcinoma (SCC), tissue polypeptide antigen, tissue polypeptide specific antigen and immunosuppressive acidic protein have been detected in patients with cervical cancer (4-7). Some of these biomarkers, such as SCC and CYFRA 21-1 have been extensively studies in regard to their potential role as prognostic indicators and predictors of therapy response during follow-up $(8,9)$. However, the biomarkers currently available have limitations in their clinical applications, such as low sensitivity and lack of specificity. Identification of new and clinically useful biomarkers for the improved detection and treatment of patients with cervical cancer remains a challenge.

The purpose of the present study was to identify candidate serum biomarkers for detection of cervical cancer. Serum samples from normal control individual and patients with cervical cancer diagnosed with different stages of the disease were studied using MARS-14 immunochromatography, followed by SDS-PAGE, in-gel digestion and liquid chromatography with tandem mass spectrometry (LC-MS/MS) analysis. The results of the present study may result in the identification of non-invasive, sensitive and specific biomarkers useful for clinical diagnosis and detection of cervical cancer.

\section{Materials and methods}

Patients. Blood samples were collected from 16 healthy females who voluntarily registered into the screening program and 31 patients with cervical cancer who were diagnosed at the
Chulabhorn Hospital (Bangkok, Thailand) between July 2014 and April 2015. Patients provided written informed consent and the study was approved by the Ethical Review Board of the Chulabhorn Hospital (approval no. 31/2554). Normal cervical status was defined as patients without diagnosis of cervical cancer. Patients with pathologically confirmed invasive carcinoma of the cervix were considered as cervical cancer cases. Exclusion criteria were as follows: Absence of cervix invasion; previous HPV vaccination; prior HPV infection; presence of any other type of cancer, with the exception of cervical cancer, during the last 5 years; or loss to follow-up throughout the program. The International Federation of Gynecology and Obstetrics staging system was used for staging in the present study (10).

Serum samples. Blood samples were maintained at room temperature for $30 \mathrm{~min}$; serum was then obtained by centrifuging the clotted blood at $3,000 \mathrm{x}$ g for $5 \mathrm{~min}$ at $4^{\circ} \mathrm{C}$. Immediately following centrifugation, a protease inhibitor cocktail (Sigma-Aldrich; Merck KGaA) was added to the serum at a ratio of 1:100 (inhibitor: Serum). Subsequently, serum samples were stored at $-80^{\circ} \mathrm{C}$ in aliquots of $50 \mu \mathrm{l}$ until further analysis. As certain proteins reflect the inflammatory state, which is typically observed in cervical cancer, controls with inflammatory conditions were included in the present study. Among the 47 participants, 16 healthy subjects were divided into two groups: HPV-negative and HPV-positive (Table I), whereas the 31 patients with cervical cancer were grouped into four groups based on cancer stage (stage I-IV), as summarized in Table II. The clinical features of healthy controls and patients with cervical cancer including age, cancer stage, HPV genotype and pathology information are presented in Tables I and II.

Cytology examination and HPV genotyping. Endocervical sampling was performed by gynecological oncologists at the Chulabhorn Hospital using a cytobrush, and samples were used for both liquid-based cytology and HPV DNA testing. All cervical cytology slides were interpreted using the Bethesda 2001 system by qualified pathologists at Chulabhorn Hospital (11). Linear array HPV testing (Roche Molecular Diagnostics) was used according to the manufacturer's protocol for the identification of $37 \mathrm{HPV}$ genotypes, including 12 high-risk (genotypes 16/18/31/33/35/39/45/51/52/56/58/59), 8 probable high-risk (genotypes 26/53/66/67/68/70/73/82) and 17 low-risk genotypes (genotypes 6/11/40/42/54/55/61/62/64/ 69/71/72/81/83/84/IS39/CP6108).

Immunoaffinity chromatography using MARS $S^{T M}$. MARS-14 columns (4.6x100 mm), purchased from Agilent Technologies, Inc., were used to deplete the 14 most abundant proteins from pooled serum samples. Albumin, immunoglobulin (Ig)G, antitrypsin, IgA, transferrin, haptoglobin, fibrinogen, $\alpha 2$-macroglobin, $\alpha 1$-acid glycoprotein, $\operatorname{IgM}$, apolipoprotein A-I, apolipoprotein A-II, complement C3 and transthyretin (TTR) were depleted at room temperature using an Agilent 1260 Infinity high performance liquid chromatography (HPLC) system. The serum samples were prepared by adding four volumes of buffer A ('Equil/load/wash'; Agilent Technologies, Inc.) and filtered to remove particulates using a 
Table I. Characteristics of normal control samples.

\begin{tabular}{lccc}
\hline Sample no. & Age & BMI & HPV genotype \\
\hline N1 & 51 & 20.55 & Negative \\
N2 & 32 & 20.45 & Negative \\
N3 & 54 & 18.32 & Negative \\
N4 & 60 & 27.83 & Negative \\
N5 & 55 & 26.08 & Negative \\
N6 & 42 & 23.49 & Negative \\
N7 & 53 & 29.31 & Negative \\
N8 & 34 & 22.63 & 16 \\
N9 & 45 & 21.06 & N/A \\
N10 & 45 & 21.01 & 52 \\
N11 & 57 & 20.07 & 51 \\
N12 & 61 & 16.60 & $52,59,72$ \\
N13 & 38 & 22.19 & 52 \\
N14 & 50 & 24.17 & 39 \\
N15 & 60 & 26.60 & $52,62,71,72$ \\
N16 & 39 & 22.07 & 59 \\
\hline
\end{tabular}

BMI, body mass index; HPV, human papillomavirus.

$0.22 \mu \mathrm{m}$ Spin-X cartridge tube filter (Corning Life Sciences). The filter was centrifuged at $16,000 \mathrm{x}$ g for $1 \mathrm{~min}$ at $4^{\circ} \mathrm{C}$ and filtrate was then ready for HPLC analysis. The HPLC system was set up by equilibrating the MARS-14 column with $100 \%$ buffer $\mathrm{A}$ at a flow rate of $0.125 \mathrm{ml} / \mathrm{min}$ for $10 \mathrm{~min}$. A total of six groups of pooled serum samples were used: Normal HPV-negative (N1-N7), normal HPV-positive (N8-N16), cervical cancer stage I (C1-C5), stage II (C6-C22), stage III (C23-C27) and stage IV (C28-C31). A total of $80 \mu 1$ of each pooled serum was loaded onto the column and the system was run for $18 \mathrm{~min}$ at the same flow rate, then run for $2 \mathrm{~min}$ with a $1 \mathrm{ml} / \mathrm{min}$ flow rate. The system was changed to $100 \%$ buffer B (elution) for $7 \mathrm{~min}$ and back to $100 \%$ of buffer A for column equilibration at a flow rate of $0.125 \mathrm{ml} / \mathrm{min}$ for $11 \mathrm{~min}$. Detection was performed at a wavelength of $280 \mathrm{~nm}$. The flow-through and bound fractions were collected and the salt buffer in each fraction was removed using a Spin-X UF concentrator (5 kDa cutoff; Corning Life Sciences) with fixed angle centrifugation at $15,000 \mathrm{x}$ g for $30 \mathrm{~min}$ at $4^{\circ} \mathrm{C}$. Protein content in the samples were determined using a Bradford assay and stored at $-80^{\circ} \mathrm{C}$ for further use.

$S D S-P A G E$ and in-gel digestion. A total of $5 \mu \mathrm{g}$ protein in bound and flow-through fractions from six sample groups (normal HPV-negative controls, normal HPV-positive controls, and patients with cervical cancer with stage I, II, III or IV) were loaded on a $10 \%$ SDS gel and resolved using SDS-PAGE. Electrophoresis was performed in a Hoefer system (Hoefer Inc.) at $10 \mathrm{~mA}$ for $15 \mathrm{~min}$. Following electrophoresis, the gels were stained with $0.1 \%$ Coomassie brilliant blue R-250 (SERVA Electrophoresis $\mathrm{GmbH}$ ) in $40 \%$ methanol and $10 \%$ acetic acid. An entire gel lane was cut into 5 similar slices and destained with $0.1 \mathrm{M} \mathrm{NH}_{4} \mathrm{HCO}_{3}$ in $50 \%$ acetonitrile (ACN). The gel pieces were dried completely using a SpeedVac Evaporator (Labconco Corporation) and the solvent was discarded. The pieces were then reduced in $50 \mu 10.1 \mathrm{M} \mathrm{NH}_{4} \mathrm{HCO}_{3}, 10 \mathrm{mM}$ DTT and $1 \mathrm{mM}$ EDTA and incubated for $45 \mathrm{~min}$ at $60^{\circ} \mathrm{C}$. Alkylation was performed using $100 \mathrm{mM}$ iodoacetamide in $0.1 \mathrm{M} \mathrm{NH}_{4} \mathrm{HCO}_{3}$ and incubated for $30 \mathrm{~min}$ at room temperature in the dark. The solution was removed, the gel pieces were dried and digested with trypsin (Promega Corporation). Following incubation at $37^{\circ} \mathrm{C}$ overnight, $1 \%$ trifluoroacetic acid was added to stop the reaction and the peptides were extracted using 5\% formic acid in $50 \%$ ACN. All solutions containing peptides were pooled and dried using SpeedVac. Samples were purified by $\mathrm{C}_{18}$ ZipTip $^{\circledR}$ (EMD Millipore) and stored at $-20^{\circ} \mathrm{C}$ until they were used for analysis.

LC-MS/MS analysis. The nanoACQUITY UltraPerformance Liquid Chromatography System (Waters Corporation) coupled with amaZon speed ion trap mass spectrometry (Bruker Corporation) with a CaptiveSpray ion source was used for peptide sample analysis. The trypsin digested samples were injected onto the C18 Nano ACQUITY BEH column, $75 \mu \mathrm{m}$ x $200 \mathrm{~mm}$ (Waters Corporation). Separation was performed at $300 \mathrm{nl} / \mathrm{min}$ with a 70 min linear gradient of $1-50 \% \mathrm{ACN}$ at $40^{\circ} \mathrm{C}$. The mass spectrometer was operated in positive ion mode with a spray voltage of $1,500 \mathrm{~V}$, dry temperature of $150^{\circ} \mathrm{C}$, without nebulizer gas and mass range between $400-1,400 \mathrm{~m} / \mathrm{z}$. The parameter was optimized at $922 \mathrm{~m} / \mathrm{z}$ with an ion charge count target of 400,000. The raw LC-MS/MS data were processed using Bruker Compass version 1.4 (Bruker Corporation). DataAnalysis ${ }^{\mathrm{TM}}$ version 4.0 (Bruker Corporation) created Mascot compatible files (.mgf) for performing Mascot database searches. The Swiss-Prot database was used with the following parameters: $2+$ and $3+$ ions, peptide tolerance $0.5 \mathrm{Da}$, fragment tolerance $0.5 \mathrm{Da}$ and the missed cleavages: 1 (12).

Data analysis. All LC-MS/MS identified proteins in bound and flow-through fractions with a score $\geq 35$ were categorized based on the molecular function, biological process and cellular component identification, and classification was performed using Protein Analysis Through Evolutionary Relationships (PANTHER) Gene Ontology Classification System (13). The identified proteins in bound and flow-through fractions were further subjected to Venn diagram analysis (14) to examine the unique and overlapping proteins between three sample groups: Normal HPV-negative; normal HPV-positive; and cervical cancer samples. The performance of a single biomarker or panels of biomarkers were used to distinguish between two clinical groups and analyzed by plotting the receiver operating characteristic (ROC) curves and calculating the area under the ROC curve (AUC) using GraphPad Prism v.5 (GraphPad Software, Inc.). Sensitivity and specificity were selected at the highest likelihood ratios. The probabilities of the panel biomarkers were calculated using binary logistic regression in SPSS (version 11.5; IBM Corp.) prior to analysis using ROC curves.

Western blot analysis. Expression of proteins of interest in pooled serum samples from healthy controls and patients with cervical cancer was determined using traditional western blot analysis. Total protein from serum was measured using 
Table II. Clinicopathological data of samples from patients with cervical cancer.

\begin{tabular}{|c|c|c|c|c|c|}
\hline $\begin{array}{l}\text { Sample } \\
\text { no. }\end{array}$ & Age & BMI & $\begin{array}{c}\text { CA } \\
\text { stage }\end{array}$ & $\begin{array}{c}\text { HPV } \\
\text { genotype }\end{array}$ & Pathology information \\
\hline $\mathrm{C} 1$ & 38 & 19.63 & IB1 & Negative & Adenocarcinoma in situ \\
\hline $\mathrm{C} 2$ & 41 & 21.23 & IB1 & 18 & Adenocarcinoma \\
\hline $\mathrm{C} 3$ & 44 & 26.37 & IB1 & 33 & Non-keratinizing squamous cell carcinoma, moderately differentiated, metastasis \\
\hline $\mathrm{C} 4$ & 55 & 25.89 & IB1 & 16 & Keratinizing squamous cell carcinoma \\
\hline C5 & 57 & 24.89 & IB2 & 53 & Keratinizing squamous cell carcinoma, poorly differentiated \\
\hline C6 & 51 & 22.56 & IIA & 16 & Squamous cell carcinoma \\
\hline $\mathrm{C} 7$ & 50 & 21.90 & IIA & 68 & Mucinous adenocarcinoma, moderately-poorly differentiated, metastasis \\
\hline $\mathrm{C} 8$ & 56 & 29.50 & IIA1 & Negative & Papillary squamous cell carcinoma \\
\hline C9 & 55 & 25.80 & IIB & Negative & Large cell non-keratinizing squamous cell carcinoma, poorly differentiated \\
\hline $\mathrm{C} 10$ & 59 & 29.09 & IIB & 18 & Adenocarcinoma, endocervical like, metastasis \\
\hline $\mathrm{C} 11$ & 62 & 27.40 & IIB & 68 & Squamous cell carcinoma \\
\hline $\mathrm{C} 12$ & 58 & 28.39 & IIB & 52 & Squamous cell carcinoma, metastasis \\
\hline $\mathrm{C} 13$ & 51 & 22.79 & IIB & 59 & Keratinizing squamous cell carcinoma \\
\hline $\mathrm{C} 14$ & 54 & 21.80 & IIB & 16 & Endometrioid adenocarcinoma \\
\hline $\mathrm{C} 15$ & 33 & 18.67 & IIB & 16 & Large cell keratinizing squamous cell carcinoma \\
\hline $\mathrm{C} 16$ & 80 & 22.60 & IIB & 58 & Non-keratinizing squamous cell carcinoma \\
\hline $\mathrm{C} 17$ & 60 & 22.09 & IIB & 16 & Squamous cell carcinoma \\
\hline $\mathrm{C} 18$ & 64 & 20.53 & IIB & 18 & Non-keratinizing squamous cell carcinoma, moderately-poorly differentiated \\
\hline $\mathrm{C} 19$ & 50 & 23.92 & IIB & 33, LR11 & Keratinizing squamous cell carcinoma, moderately differentiated \\
\hline $\mathrm{C} 20$ & 62 & 23.51 & IIB & 18 & Squamous cell carcinoma \\
\hline $\mathrm{C} 21$ & 64 & 31.23 & IIB & Negative & Endometrial adenocarcinoma, moderately differentiated, metastasis \\
\hline $\mathrm{C} 22$ & 61 & 27.04 & IIB & LR 72 & Endocervical adenocarcinoma, poorly differentiated, metastasis \\
\hline $\mathrm{C} 23$ & 49 & 23.88 & IIIB & Negative & Carcinoma, malignant neoplasm of exocervix \\
\hline $\mathrm{C} 24$ & 50 & 13.28 & IIIB & Negative & Keratinizing squamous cell carcinoma \\
\hline $\mathrm{C} 25$ & 42 & 23.21 & IIIB & 16 & Non-keratinizing squamous cell carcinoma, moderately differentiated \\
\hline $\mathrm{C} 26$ & 61 & 28.07 & IIIB & 16 & Non-keratinizing squamous cell carcinoma, well-moderately differentiated \\
\hline $\mathrm{C} 27$ & 58 & 23.13 & IIIB & 31 & Non-keratinizing squamous cell carcinoma, moderately differentiated, metastasis \\
\hline $\mathrm{C} 28$ & 49 & 17.94 & IVA & 52,33 & Non-keratinizing squamous cell carcinoma, moderately differentiated \\
\hline $\mathrm{C} 29$ & 49 & 25.76 & IVB & 18 & Squamous cell carcinoma, poorly differentiated \\
\hline $\mathrm{C} 30$ & 59 & 22.98 & IVB & 52 & Non-keratinizing squamous cell carcinoma, moderately differentiated, metastasis \\
\hline $\mathrm{C} 31$ & 43 & 18.27 & IVB & 18,51 & Adenocarcinoma, metastasis \\
\hline
\end{tabular}

BMI, body mass index; HPV, human papillomavirus; CA, cancer antigen.

a Bradford assay and $25 \mu \mathrm{g}$ of protein were separated by $12.5 \%$ SDS-PAGE and transferred onto PVDF membranes (GE Healthcare). Membranes were blocked in $3 \%(\mathrm{w} / \mathrm{v})$ BSA (Sigma-Aldrich; Merck KGaA) in TBS containing $0.1 \%$ Tween-20 (TBS-T) for $1 \mathrm{~h}$ at room temperature, the membrane was probed with the following primary antibodies: Rabbit anti-vitamin D binding protein (VDBP; 1:2,500; cat. no. ab81307; Abcam), rabbit anti-transthyretin (TTR; 1:2,500; cat. no. ab75815; Abcam), rabbit anti- $\alpha 1$ antitrypsin (A1AT; 1:200; cat. no. ab167414; Abcam), rabbit anti-pyrroline-5-carboxylate reductase 2 (PYCR2; 1:500; cat. no. ab103535; Abcam), rabbit anti-multimerin-1 (MMRN1; 1:1,000; cat. no. ab130585; Abcam) and mouse anti-apolipoprotein A-I (ApoA-I; 1:5,000; cat. no. 3350; Cell Signaling Technology, Inc.) at $4^{\circ} \mathrm{C}$ overnight. The membranes were subsequently washed with TBS-T and incubated with an appropriate secondary antibody conjugated with horseradish peroxidase
(1:5,000; cat. no. P0217 (Rabbit) and P0260 (Mouse); Dako; Agilent Technologies, Inc.) for $1 \mathrm{~h}$ at room temperature. After three washes with TBS-T, protein bands were visualized using a WesternBright ECL detection kit (Advansta Inc.).

Capillary western blot analysis. Capillary electrophoresis was performed to investigate the differentially expressed proteins in serum from each patient individually using the Wes Simple Western Analysis (ProteinSimple). The assays were performed according to the manufacturer's protocol with $5 \mu \mathrm{g}$ total protein. Samples were mixed with SDS-containing sample buffer, fluorescent molecular weight markers and $400 \mathrm{mM}$ of DTT. The sample mixture was heated at $95^{\circ} \mathrm{C}$ for $5 \mathrm{~min}$ and run on $12-230 \mathrm{kDa}$ assay capillaries using the default parameters. The proteins were probed with the following primary antibodies: Rabbit anti-VDBP (1:50); rabbit anti-TTR (1:10,000); rabbit anti-A1AT (1:75); rabbit anti-PYCR2 (1:5); 
A

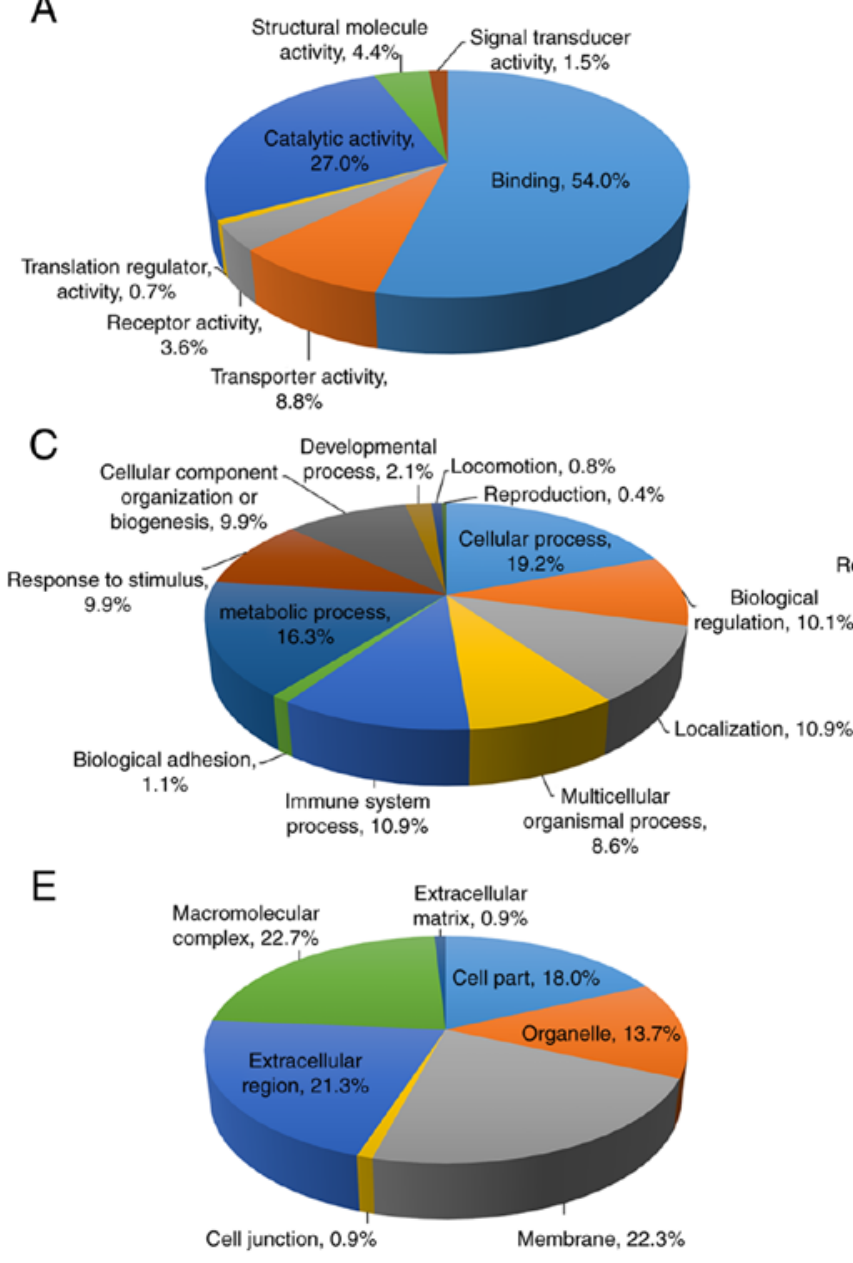

B

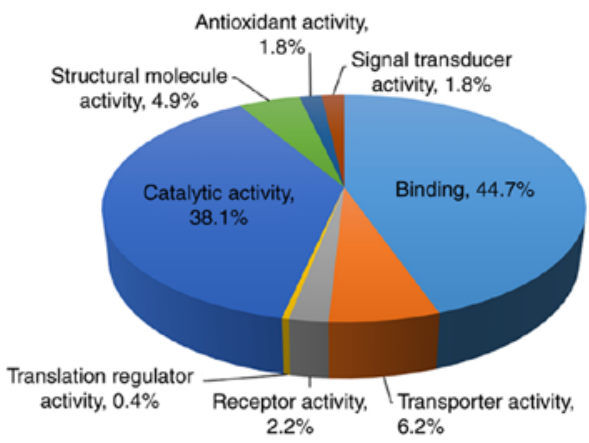

D

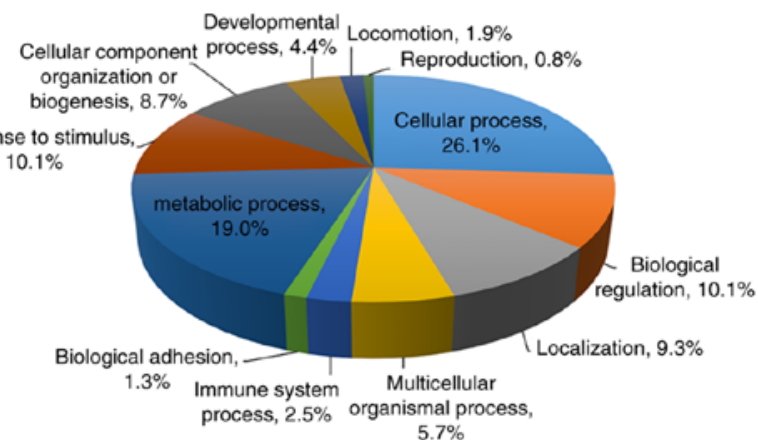

$\mathrm{F}$

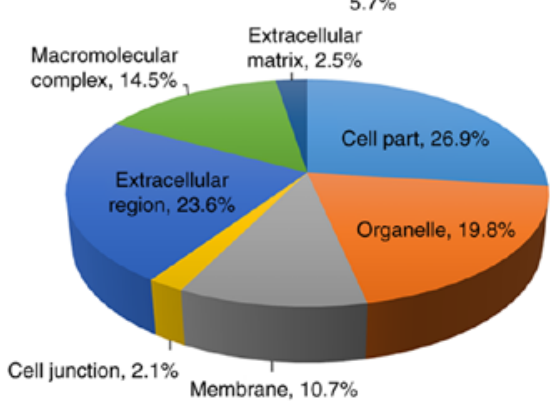

Figure 1. Gene Ontology analysis of the proteins identified by liquid chromatography mass spectrometry in the bound and flow-through fractions. (A and B) Molecular functions of the (A) bound and (B) flow-through fractions. (C and D) Biological processes of the (C) bound and (D) flow-through fractions. (E and F) Cellular compartments of proteins in the (E) bound and (F) flow-through fractions were determined using the Protein Analysis Through Evolutionary Relationships classification system.

rabbit anti-MMRN1 (1:100); and mouse anti-ApoA-I $(1: 25,000)$ and visualized using HRP-conjugated rabbit or mouse secondary antibodies [no dilution; cat. no. 042-206 (rabbit), 042-205 (mouse)] and luminol-peroxide mixture (ProteinSimple). Chemiluminescence images were captured and data was analyzed using Compass (ProteinSimple). The relative quantities of each target protein band was determined based on peak area and normalized against the intensity of total protein content.

Statistical analysis. Automated western blot data were analyzed using GraphPad Prism (version 5). Data are presented as mean \pm standard deviation. To determine differences between multiple groups, a one-way analysis of variance with a post-hoc Tukey's test was performed. $\mathrm{P}<0.05$ was considered to indicate a statistically significant difference.

\section{Results}

Protein identification using LC-MS/MS. A total of six groups of pooled serum samples [normal HPV-negative (N1-N7); normal HPV-positive (N8-N16); cervical cancer stage I (C1-C5); stage II (C6-C22); stage III (C23-C27) and stage IV
(C28-C31)] were fractionated using a MARS-14 column. The flow-through (appearing from 8-13 min) and bound (appearing from 22-23 $\mathrm{min}$ ) fractions were collected. All 12 fractions (6 flow-through and 6-bound) were separated using SDS-PAGE. A total of 60 gel bands were trypsinized and identified by LC-MS/MS. Protein identification revealed a total of 724 and 967 proteins in the bound and the flow-through fractions, respectively. Keratins were removed from the protein lists and the remaining proteins with a score $\geq 35$ were selected for further study.

Classification, functional analysis and Venn diagram analysis of the identified proteins. All LC-MS/MS identified proteins with a score $\geq 35$ in bound ( 341 proteins) and flow-through fractions (563 proteins) are summarized in Tables SI and SII and were further analyzed for Gene Ontology using the PANTHER classification system. The proteins were categorized according to their 'molecular function', 'biological process' and 'cellular compartment', as demonstrated in Fig. 1.For proteins in the bound fraction, the molecular functions were classified into 7 groups, with the majority of proteins being involved in binding (54.0\%), followed by catalytic activity (27.0\%) (Fig. 1A). The biological process analysis classified these proteins into 12 groups and the 
majority of proteins were involved in cellular process (19.2\%), followed by metabolic process (16.3\%) (Fig. 1C). Gene Ontology analysis for cellular compartments classified these proteins into 7 groups, and the macromolecular complex was the most common cellular compartment $(22.7 \%)$, followed by membrane (22.3\%) and extracellular region (21.3\%) (Fig. 1E). For the flow-through fraction, the molecular functions were classified into 8 groups, with the most abundant proteins involved in binding (44.7\%), followed by catalytic activity (38.1\%) (Fig. 1B). Similar to the bound fraction, the biological processes of these proteins were classified into 12 groups with the most commonly identified being cellular process (26.1\%), followed by metabolic process (19.0\%) (Fig. 1D). The proteins were classified according to the cellular compartments into 7 groups, and were primarily involved in cell part (26.9\%), extracellular region (23.6\%) and organelle (19.8\%) (Fig. 1F).

Venn diagram analysis demonstrated the unique and overlapping proteins between controls and patient samples in the bound and flow-through fractions (Fig. 2A and B). Overlapping regions indicated the proteins common or partially common to each sample group. The number of unique or overlapping proteins are indicated in Fig. 2. A total of 82 and 167 common proteins between the 3 datasets in bound and flow-through fractions were identified, respectively. There were 24,35 and 142 unique proteins in the normal HPV-negative, normal HPV-positive and patients with cervical cancer groups, respectively, in the bound fraction. For the flow-through fraction, 48, 50 and 207 proteins were uniquely identified in the normal HPV-negative, normal HPV-positive and patients with cervical cancer groups, respectively. Among the 207 proteins uniquely identified in the flow-through fraction of patients with cervical cancer, 2 proteins that have been previously unreported in cervical cancer, PYCR2 and isoform-2 of MMRN1, were selected for further evaluation as cervical cancer biomarkers. VDBP, identified in the flow-through fraction of both normal controls and patients with cervical cancer, has been extensively studied in various types of cancer, but the association between VDBP levels and the risk of cancer remains controversial; therefore, VDBP was selected for further study. Furthermore, certain MARS-14 targeted acute phase proteins, such as A1AT, TTR and ApoA-I, have been associated with distinct stages in various types of cancer. Acute phase proteins may serve as diagnostic biomarkers as they reflect a systemic inflammatory response often observed in a number of types of cancer, including cervical cancer. The changes in the levels of A1AT, TTR and ApoA-I were therefore determined in the validation set of serum samples.

AlAT, PYCR2, TTR, ApoA-I, VDBP and isoform-2 of $M M R N 1$ are differentially expressed in serum from patients with cervical cancer. Traditional western blot analysis was performed on the six groups of pooled serum samples from healthy controls and patients with cervical cancer. The results indicated that numerous proteins exhibited differential serum expression levels between the groups. The expression of A1AT and PYCR2 was elevated in serum from patients with cervical cancer and the increased expression was associated with advanced cancer stages. Another 4 proteins, VDBP, TTR, ApoA-I and isoform-2 of MMRN1, were demonstrated to be downregulated in serum in patients with cervical cancer compared with the normal controls (Fig. 3).
A

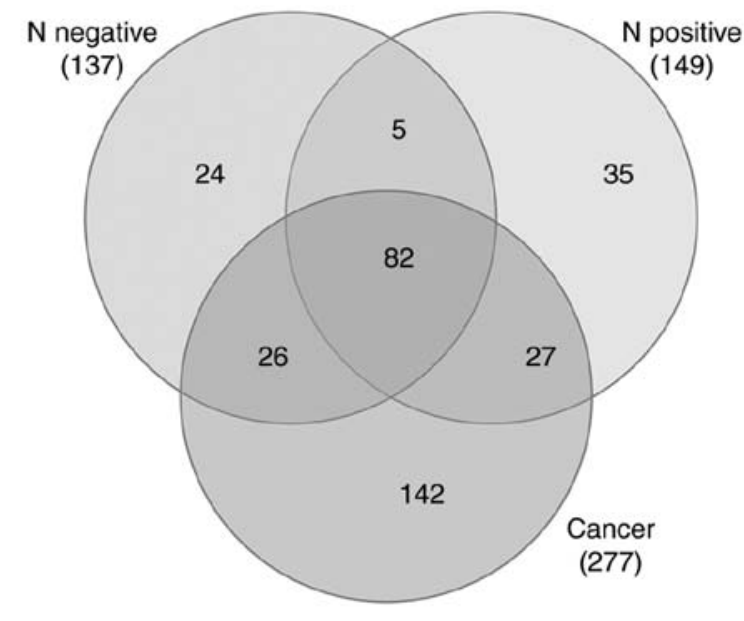

B

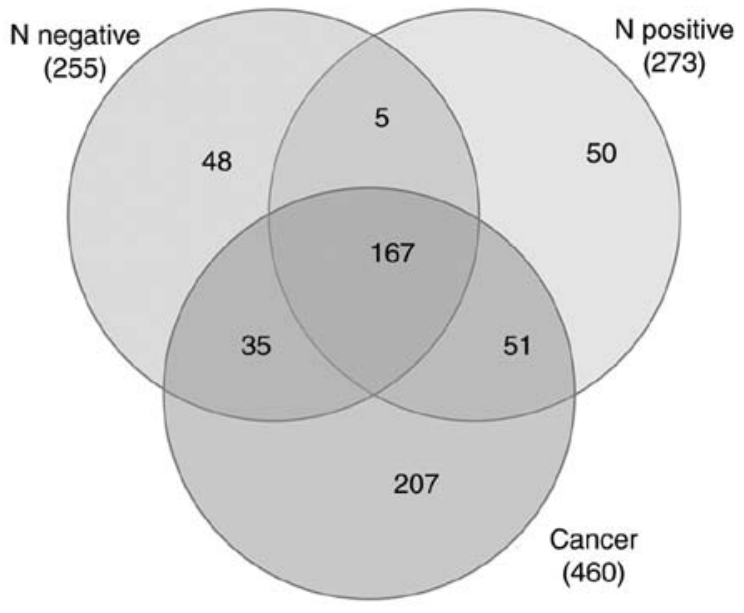

Figure 2. Venn diagrams of the proteins identified by liquid chromatography mass spectrometry in the bound and flow-through fractions. Venn diagram showing unique and overlapping proteins in (A) bound and (B) flow-through fractions between the three sample groups: $\mathrm{N}$ negative; $\mathrm{N}$ positive; and patients with cervical cancer. N negative, Normal controls with HPV negative; $\mathrm{N}$ positive, normal controls with HPV positive.

Quantitative western blot analysis was used to further validate the diagnostic potential of these proteins in each individual case. As presented in Fig. 4, serum levels of A1AT were significantly increased in the stage III-IV group compared with the normal HPV-negative control group $(\mathrm{P}<0.01)$, the normal HPV-positive control group $(\mathrm{P}<0.001)$ and stage I-II group $(\mathrm{P}<0.01)$. The results also demonstrated significantly increased expression levels of PYCR2 in the stage III-IV group compared with the normal HPV-positive control group $(\mathrm{P}<0.01)$ and the stage I-II group $(\mathrm{P}<0.01)$. The expression of TTR was significantly decreased in the stage III-IV group compared with the normal HPV-negative control group $(\mathrm{P}<0.05)$ and the stage I-II group $(\mathrm{P}<0.05)$. The ApoA-I levels were significantly downregulated in the stage III-IV group $(\mathrm{P}<0.01)$ and the stage I-II group $(\mathrm{P}<0.01)$ compared with the normal HPV-negative control group. The VDBP expression levels were significantly downregulated in the serum from the normal HPV-positive control group $(\mathrm{P}<0.05)$, the stage I-II group $(\mathrm{P}<0.01)$ and the stage III-IV group $(\mathrm{P}<0.05)$ compared with the normal HPV-negative control group. In addition to being significantly decreased in serum from 
A

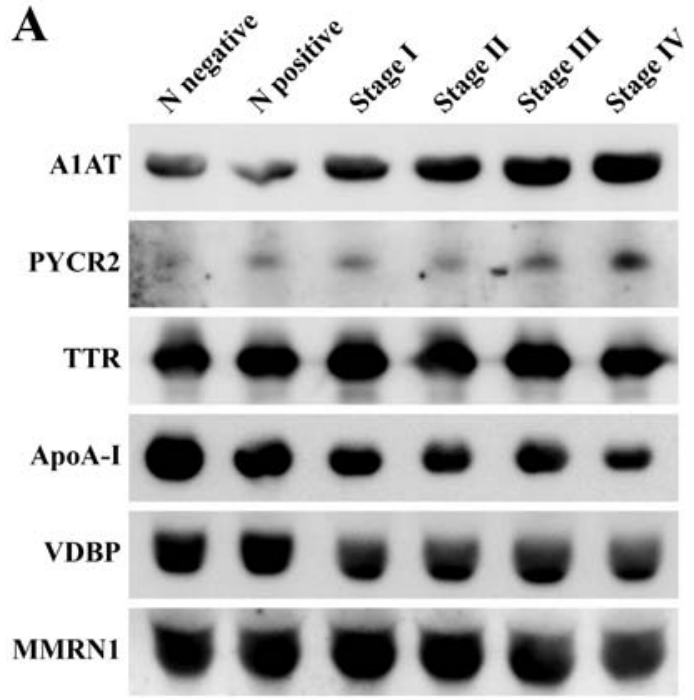

B

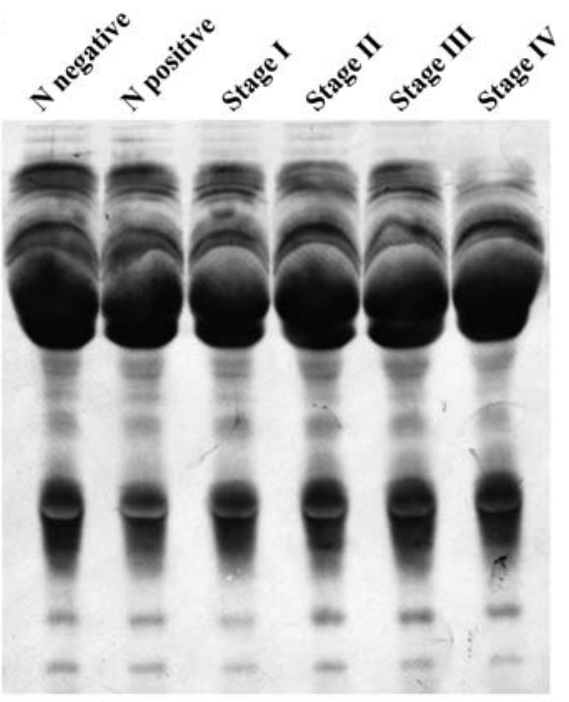

Figure 3. Western blot analysis. (A) Levels of A1AT, VDBP, TTR, ApoA-I, MMRN1 and PYCR2 in pooled serum samples from N negative, N positive and stage I-IV cervical cancer patients. (B) A Coomassie-stained western blot membrane indicating the total protein profile as a loading control. $\mathrm{N}$ negative, Normal controls with HPV negative; N positive, normal controls with HPV positive; A1AT, $\alpha$-1-antitrypsin; PYCR2, pyrroline-5-carboxylate reductase 2; TTR, transthyretin; ApoA-I, apolipoprotein A-I; VDBP, vitamin D binding protein; MMRN1, multimerin-1.

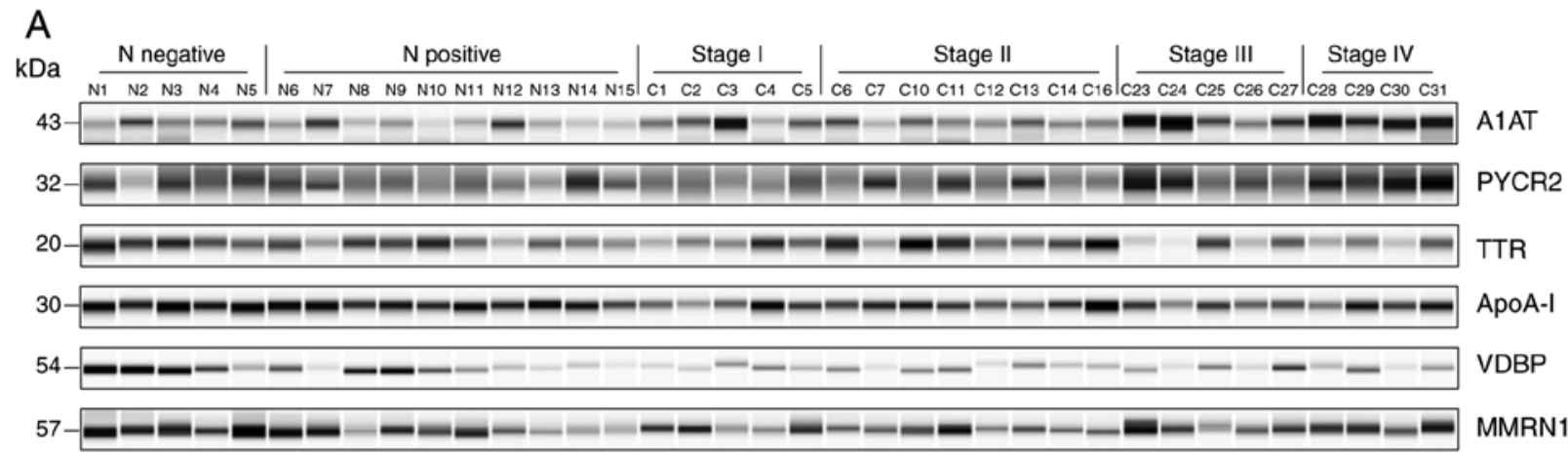

B
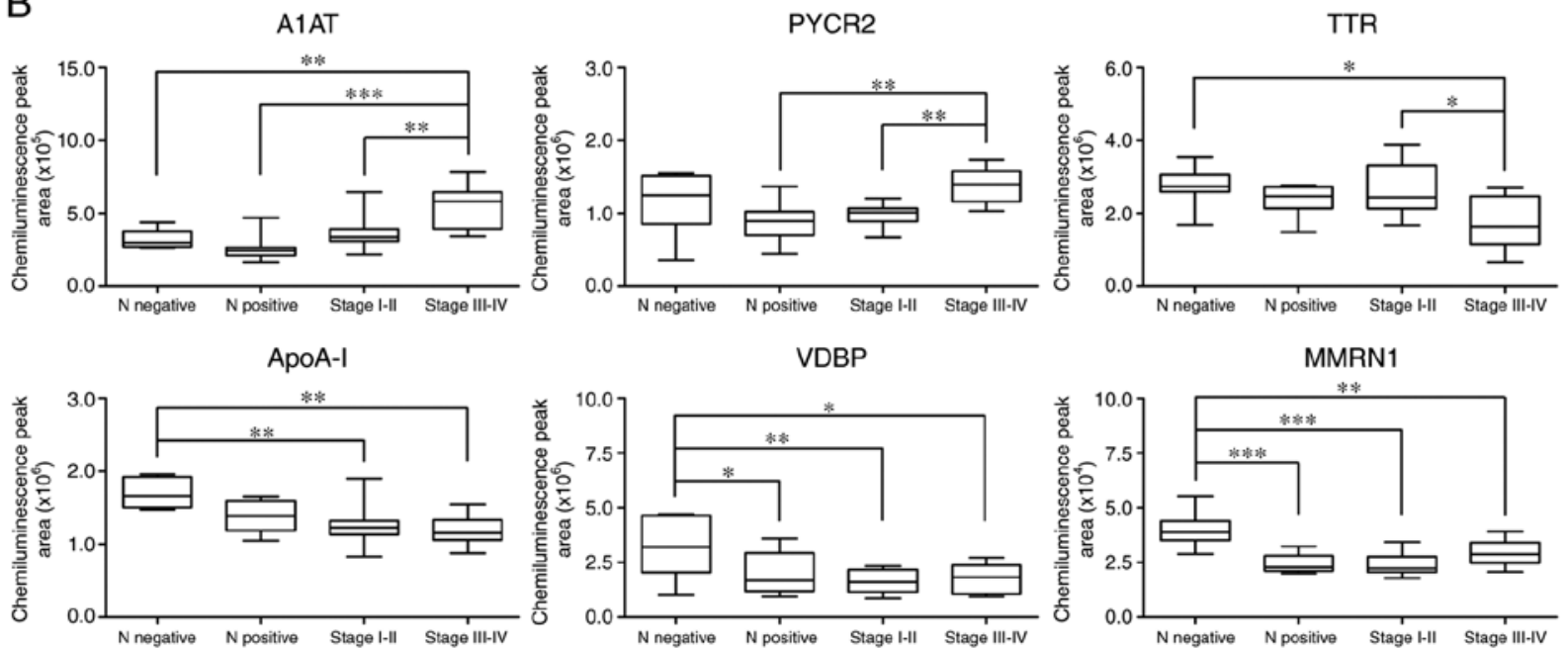

Figure 4. Quantitative measurement of protein expression levels using capillary electrophoresis. (A) Electropherogram of the A1AT, PYCR2, TTR, ApoA-I, VDBP and isoform-2 of MMRN1 levels in serum samples from the HPV negative normal controls (N1-N5), HPV positive normal controls (N6-N15), and patients with stage I (C1-C5), stage II (C6, C7, C10-C14 and C16), stage III (C23-C27) and stage IV (C28-C31) cervical cancer. (B) Box plots demonstrating the distribution of protein expression in serum samples from the normal and stage I-IV cervical patients. ${ }^{*} \mathrm{P}<0.05,{ }^{* *} \mathrm{P}<0.01$ and ${ }^{* * *} \mathrm{P}<0.001$. A1AT, $\alpha-1$-antitrypsin; PYCR2, pyrroline-5-carboxylate reductase 2; TTR, transthyretin; ApoA-I, apolipoprotein A-I; VDBP, vitamin D binding protein; MMRN1, multimerin-1.

the stage III-IV group compared with the normal HPV-negative control group $(\mathrm{P}<0.01)$, the expression levels of isoform-2
MMRN1 were also decreased in serum from the stage I-II group $(\mathrm{P}<0.001)$ and the normal HPV-positive control group $(\mathrm{P}<0.001)$. 
A panel of 6 candidate biomarkers improves detection. ROC curves were constructed to assess the performance of candidate biomarkers to discriminate between sample groups. The diagnostic accuracy of numerous combinations of A1AT, PYCR2, TTR, ApoA-I, VDBP and MMRN1 were also examined using a binary logistic regression model (Table SIII). Individually, the AUC values ranged from 0.539 (VDBP, for discriminating between early-stage vs. late stage cervical cancer groups) to 0.982 (MMRN1, for discriminating between normal HPV-negative vs. HPV-positive controls). Notably, a combination of 6 biomarkers yielded an increased predictive accuracy with the highest AUC value of 1.000 (sensitivity of $100 \%$ and specificity of $85.7 \%$ ), which was increased compared with that of any individual biomarker, with the exception of MMRN1, for discriminating between the HPV-negative and HPV-positive normal controls. The best models for the differential diagnosis of the normal HPV-negative controls, normal HPV-positive controls, and early-stage and late stage cervical cancer samples are presented in Fig. 5.

\section{Discussion}

Cervical cancer, unlike most other types of cancer, is a potentially preventable disease with the use of vaccination and screening tests to detect precancerous lesions. The 5-year survival rate of patients with cervical cancer at advanced-stage is only $15-35 \%$ (15); however, it is $>90 \%$ when detected in the early, treatable stages (16). Therefore, early detection is important for decreasing the incidence and mortality rates of cervical cancer. The identification of non-invasive biomarkers for detection of cervical cancer, therefore, is a high priority. In the present study, the western blot analysis results indicated the differential abundance of 6 proteins between healthy controls and patients with cervical cancer, and among different stages of cancer, which were A1AT, PYCR2, TTR, ApoA-I, VDBP and MMRN1. The significantly different expression profiles of these proteins in each individual case was successfully validated by quantitative examination using capillary electrophoresis.

Human A1AT, a serine protease inhibitory, is a serum glycoprotein which serves a central role in tissue protection through its inhibitory effects on enzymes in inflammatory cells, including trypsin, chymotrypsin, neutrophil elastase and thrombin. A1AT is primarily expressed in the liver; however, previous studies have indicated that a number of different types of cancer cells, including lung, prostate, thyroid, pancreatic and breast cancer cells, are capable of expression and secretion of A1AT $(17,18)$. The results of the present study revealed that A1AT expression levels were significantly upregulated in patients with stage III-IV cervical cancer, and that it could be used to differentiate between patients with advanced-stage cervical cancer and those with stage I-II cancer and non-cancerous healthy controls. Upregulation of A1AT serum levels has also been observed in different types of malignancies, such as hepatocellular carcinoma, lung, prostate, breast, pancreatic and colorectal cancer $(17,19,20)$. In addition, the positive association between upregulation of A1AT expression levels with cancer staging has been demonstrated in different types of cancer $(21,22)$. El-Akawi et al (23) demonstrated the potential use of A1AT blood levels as an indicator of lung and prostate cancer treatment.

PYCR2 is a mitochondrial enzyme and a member of the PYCR family of proteins, which catalyzes the final step of proline synthesis by conversion of pyrroline-5-carboxylate (P5C) to proline. Unlike PYCR1, another isozyme in the PYCR family that has been demonstrated to be one of the most frequently overexpressed enzymes in cancer (24) and correlated with invasiveness and poor outcomes of breast cancer (25), relatively less is known about the role of PYCR2 in cancer. A few studies have revealed that PYCR2 is essential for cell proliferation $(26,27)$. In the present study, the expression levels of PYCR2 were increased significantly in patients with advanced-stage cervical cancer, compared with patients with early-stage cervical cancer and with HPV positive normal controls. This was consistent with a previous study demonstrating that the upregulated levels of PYCR2 were observed in a panel of melanoma cell lines, but not in normal melanocytes (28). In addition, it has been demonstrated that the expression of PYCR 2 is induced by two frequently constitutively expressed oncogenic transcription factors, c-MYC and PI3K $(27,29)$. To the best of our knowledge, the results of the present study are the first to demonstrate the association between PYCR2 and cervical cancer.

TTR, also known as vitamin A, is a homo-tetrameric protein primarily synthesized by the liver and choroid plexus in the brain, and is involved in the transport of thyroid hormone thyroxine and retinol. TTR has been previously used in nutritional indexes, due to the association between its plasma levels and the nutritional supply. TTR levels were identified to be decreased in the sera of various cancer types, such as lung, prostate, gastric, ovarian, pancreatic cancer, cholangiocarcinoma and chronic myeloid leukemia (30-36); therefore, TTR may be considered a potential biomarker. Consistent with these studies, the results from the present study indicated significantly decreased TTR levels in the sera of patients with advanced-stage cervical cancer, compared with the HPV negative normal controls and patients with early-stage cervical cancer. In addition, the TTR levels demonstrated an inverse correlation with tumor volume in gastric and ovarian cancer (32,37), were associated with prostate cancer stage (31) and serve as a therapy-associated biomarker in patients with chronic myeloid leukemia (36). It has been well established that the liver increases the production of positive acute phase reactants and decreases the production of negative acute phase reactants in response to insults, including trauma in the body, inflammation, infection and malignancy. As A1AT is a positive acute phase reactant and TTR is a negative acute phase reactant, the results of the present study, which demonstrated an increase in serum A1AT levels concomitant with a reduction in TTR levels, are in concordance with these established trends.

ApoA-I, the major structural protein of high-density lipoprotein, is predominantly synthesized in the liver (70\%) and the small intestine (30\%). ApoA-I is considered atheroprotective as it participates in transporting excess cholesterol from tissues to the liver for excretion, a process called reverse cholesterol transport. Previous studies have indicated that ApoA-I also demonstrated antioxidant, 

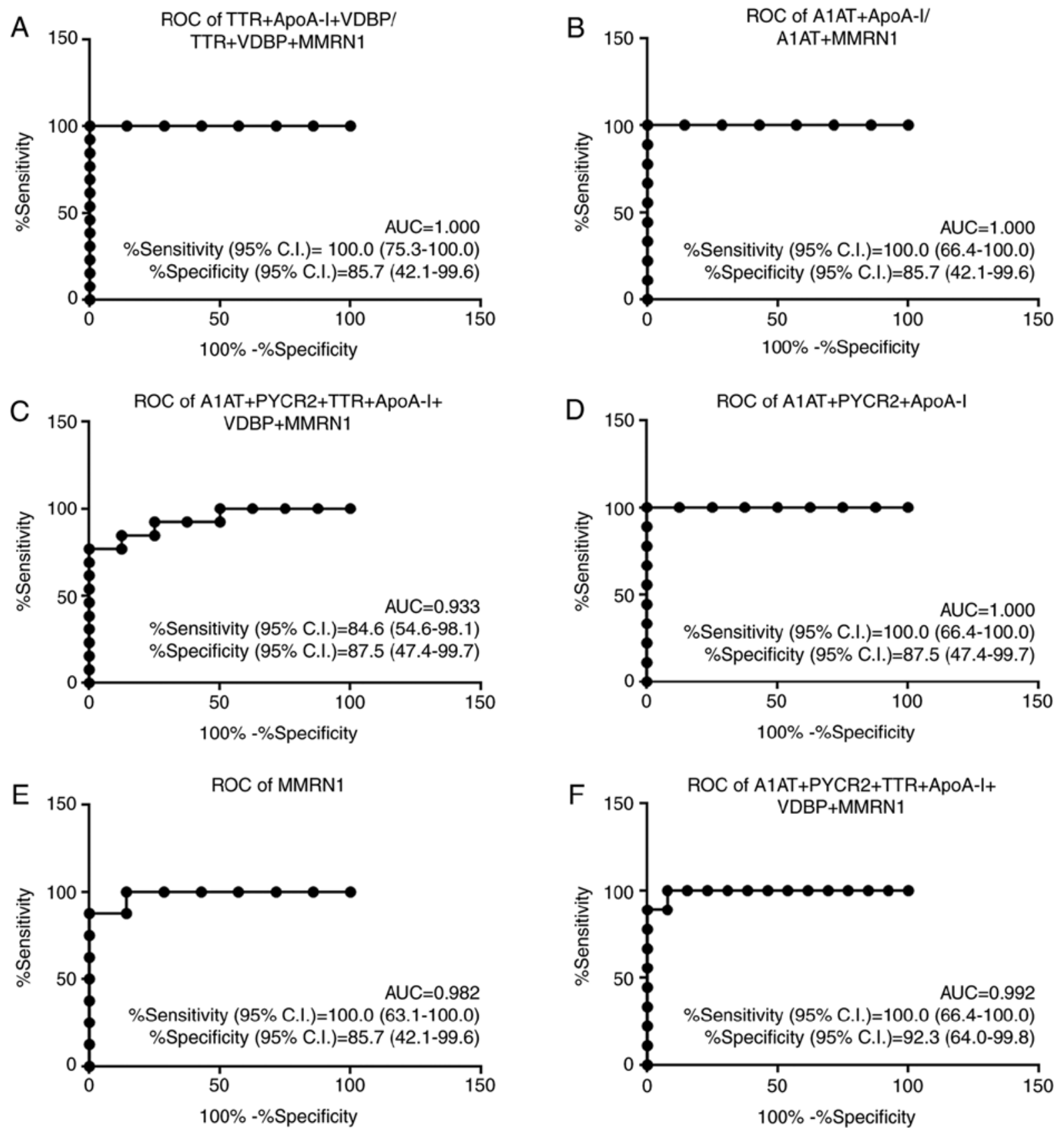

Figure 5. Performance of the best marker models for each comparison. AUC, sensitivity with 95\% CI and specificity with 95\% CI are stated. (A) Comparison of normal controls with HPV-negative vs. early-stage (N- vs. E). (B) Comparison of normal controls with HPV-negative vs. late stage (N- vs. L). (C) Comparison of normal controls with HPV-positive vs. early-stage (N+ vs. E). (D) Comparison of normal controls with HPV-positive vs. late stage (N+ vs. L). (E) Comparison of normal controls with HPV-negative vs. normal controls with HPV-positive (N- vs. N+). (F) Comparison of early-stage vs. late stage cervical cancer (E vs. L). ROC, receiver operating characteristic; AUC, area under the ROC curve; CI, confidence interval; A1AT, $\alpha$-1-antitrypsin; PYCR2, pyrroline-5-carboxylate reductase 2; TTR, transthyretin; ApoA-I, apolipoprotein A-I; VDBP, vitamin D binding protein; MMRN1, multimerin-1.

anti-inflammatory and anti-apoptotic effects (38-40). Recent studies have reported that ApoA-I inhibits cell proliferation in vitro and suppresses tumor growth and metastasis in vivo in animal models expressing ApoA-I $(41,42)$. Similar to TTR, ApoA-I is a negative acute phase reactant and serum ApoA-I levels are inversely associated with systemic inflammation, advanced cancer stage and poor patient survival (43). The results of the present study, which were consistent with previous studies, demonstrated that ApoA-I expression levels were significantly decreased in patients with cervical cancer, at both early and advanced-stages of the disease, compared with the HPV negative normal controls. Previous studies have identified that decreased serum ApoA-I levels are associated with a number of different types of cancer, including ovarian, breast, pancreatic, colorectal and gastric cancer (34,44-46).

VDBP, also known as Gc-globulin, belongs to the multigene family of proteins that includes albumin and $\alpha$-fetoprotein. VDBP is synthesized and secreted predominantly by the liver and is the major protein involved in transporting vitamin $\mathrm{D}$ and its metabolites to target tissues. In addition to its role in vitamin D transport, other important biological 
functions of VDBP include extracellular G-actin scavenging, macrophage activation (immuno-modulatory function) and neutrophil chemotaxis (anti-inflammatory function) $(47,48)$. Previous studies have suggested an association between low levels of VDBP and the risk of several types of cancer, including multiple myeloma, pancreatic, prostate and kidney cancer (49-51). These previous data were supported by the inverse association between serum VDBP levels and cervical cancer observed in the present study. Significantly decreased serum levels of VDBP were observed in patients with cervical cancer, in both patients with early and advanced-stage cancer, and also in HPV positive normal controls compared with HPV negative normal controls. However, controversial results have been observed regarding the association between VDBP levels and the risk of certain types of cancer, including colorectal and bladder cancer $(52,53)$.

MMRN1, also known as elastin microfibril interface located protein 4 , is a soluble homopolymeric glycoprotein identified in $\alpha$ granules in platelets and endothelial cells. MMRN1 may serve as a carrier protein for platelet factor $\mathrm{V}$, and serve as an adhesion protein via integrin receptors and the extracellular matrix. MMRN1 has been reported as an adverse marker in pediatric acute myeloid leukemia (AML). An association between MMRN1 expression and clinical outcomes indicated that high MMRN1 expression levels were correlated with shorter overall survival, event-free survival and a higher relapse risk of AML (54). The 5-year survival rate of patients with high MMRN1 expression is $27 \%$ and low MMRN1 expression levels are observed in $66 \%$ of patients with stomach cancer (55). Similarly, 5-year survival rates of 65 and $80 \%$ was reported for high and low levels of MMRN1 expression, respectively for renal cancer (56), indicating the prognostic value of MMRN1 in stomach and renal cancer. MMRN1 has 2 isoforms, each measuring 138 and $58 \mathrm{kDa}$, due to alternative splicing. Isoform-1 of MMRN-1 has been identified as a potential serum biomarker for multiple myeloma and lung cancer (49) and urinary biomarker for cervical cancer (57). In the present study, serum levels of isoform-2 of MMRN-1, as confirmed by mass spectrometry, were decreased in the serum of HPV positive normal controls and in patients with early and late stage cervical cancer. To the best of our knowledge, the present is the first study to demonstrate that isoform-2 of multimerin-1 was associated with cervical cancer.

In conclusion, 6 candidate biomarkers, A1AT, PYCR2, TTR, ApoA-I, VDBP and isoform-2 of MMRN1, were identified to be differentially expressed between serum samples from healthy controls and patients with cervical cancer. A1AT and PYCR2 levels were significantly increased, whereas the levels of TTR, ApoA-I, VDBP and isoform-2 of MMRN1 were significantly decreased in patients with cervical cancer. To the best of our knowledge, PYCR2 and isoform-2 of MMRN1 were identified to be potentially involved in cervical cancer for the first time. Furthermore, ROC curve analysis supported the potential of use of these candidate biomarkers to distinguish between patients with cervical cancer and healthy controls, and for differentiating between patients with early-stage and advanced-stage cervical cancer. Additionally, a panel of 6 candidate biomarkers was identified to perform better compared with the majority of the individual biomarkers alone for prediction and discrimination.
Therefore, the results of this pilot study, using relatively a small sample size, suggested that these candidate biomarkers may potentially be used for detection of cervical cancer and that combining the biomarkers increased the sensitivity and specificity. Further validation will be required using an independent sample set with a larger cohort, including patients with precancerous lesions, in order to evaluate the potential of these candidate biomarkers as prognostic indicators of cervical cancer.

\section{Acknowledgements}

Not applicable.

\section{Funding}

The present study was supported by the Chulabhorn Research Institute (grant no. BC 2008-02) and Chulabhorn Royal Academy (grant no. 31/2554).

\section{Availability of data and materials}

The datasets used and/or analyzed during the current study are available from the corresponding author on reasonable request.

\section{Authors' contributions}

SK and PS performed the experiments, including immunoaffinity chromatography, sample preparation for mass spectrometry, classical and automated western blot analysis and data analysis. CS and SK wrote the manuscript. DC performed the mass spectrometry. PS and DC helped in preparing the manuscript. CS and CW designed the study, developed the methodology and interpreted the results obtained. KS performed statistical and bioinformatics analyses. NS performed the clinical data collection, provided the HPV genotyping data and contributed to ethical information in the materials and methods of manuscript. NK performed the patient recruitment, surgery and treatment on enrolled subjects. KW performed serum sample collection and data analysis. TS performed the histological examination and provided pathology information. JS supervised the quality of design and gave final approval of the manuscript prior to submission. JS, CA and NMP provided technical assistance and were involved in the study design. All authors read and approved the final manuscript.

\section{Ethics approval and consent to participate}

The present study was approved by the Ethical Review Board of the Chulabhorn Hospital (no. 31/2554), and written informed consent was obtained from the patients.

\section{Patient consent for publication}

Patients provided written informed consent.

\section{Competing interests}

The authors declare that they have no competing interests. 


\section{References}

1. Oldham RK and Dillman RO (eds): Principles of Cancer Biotherapy. Springer Science and Business Media, New York, NY, 2009.

2. Canavan TP and Doshi NR: Cervical cancer. Am Fam Physician 61: 1369-1376, 2000.

3. Litjens RJ, Hopman AH, van de Vijver KK, Ramaekers FC Kruitwagen RF and Kruse AJ: Molecular biomarkers in cervical cancer diagnosis: A critical appraisal. Expert Opin Med Diagn 7: 365-377, 2013.

4. Pras E, Willemse PH, Canrinus AA, de Bruijn HW, Sluiter WJ, ten Hoor KA, Aalders JG, Szabo BG and de Vries EG: Serum squamous cell carcinoma antigen and CYFRA 21-1 in cervical cancer treatment. Int J Radiat Oncol Biol Phys 52: 23-32, 2002.

5. Gaarenstroom K, Bonfrer J, Korse C, Kenter G and Kenemans P Value of Cyfra 21-1, TPA, and SCC-Ag in predicting extracervical disease and prognosis in cervical cancer. Anticancer Res 17: 2955-2958, 1997.

6. Borras G, Molina R, Xercavins J, Ballesta A and Iglesias J: Tumor antigens CA 19.9, CA 125, and CEA in carcinoma of the uterine cervix. Gynecol Oncol 57: 205-211, 1995

7. Battaglia F, Scambia G, Panici PB, Castelli M, Ferrandina G, Foti E, Amoroso M, D'Andrea G and Mancuso $S$ : Immunosuppressive acidic protein (IAP) and squamous cell carcinoma antigen (SCC) in patients with cervical cancer. Gynecol Oncol 53: 176-182, 1994

8. Suzuki Y, Nakano T, Ohno T, Abe A, Morita S and Tsujii $\mathrm{H}$ : Serum CYFRA 21-1 in cervical cancer patients treated with radiation therapy. J Cancer Res Clin Oncol 126: 332-336, 2000.

9. Forni F, Ferrandina G, Deodato F, Macchia G, Morganti AG, Smaniotto D, Luzi S, D'Agostino G, Valentini V, Cellini N, et al: Squamous cell carcinoma antigen in follow-up of cervical cancer treated with radiotherapy: Evaluation of cost-effectiveness. Int J Radiat Oncol Biol Phys 69: 1145-1149, 2007.

10. FIGO Committee on Gynecologic Oncology: FIGO staging for carcinoma of the vulva, cervix, and corpus uteri. Int J Gynaecol Obstet 125: 97-98, 2014.

11. Apgar BS, Zoschnick L and Wright TC Jr: The 2001 Bethesda system terminology. Am Fam Physician 68: 1992-1998, 2003

12. The UniProt Consortium: UniProt: A worldwide hub of protein knowledge. Nucleic Acids Res 47: D506-D515, 2019.

13. Mi H, Muruganujan A, Huang X, Ebert D, Mills C, Guo X and Thomas PD: Protocol update for large-scale genome and gene function analysis with the PANTHER classification system (v.14.0). Nat Protoc 14: 703-721, 2019.

14. Heberle H, Meirelles GV, da Silva FR, Telles GP and Minghim R: InteractiVenn: A web-based tool for the analysis of sets through Venn diagrams. BMC Bioinformatics 16: 169, 2015.

15. Maranga IO, Hampson L, Oliver AW, Gamal A, Gichangi P, Opiyo A, Holland CM and Hampson IN: Analysis of factors contributing to the low survival of cervical cancer patients undergoing radiotherapy in Kenya. PLoS One 8: e78411, 2013.

16. Zampronha Rde A, Freitas-Junior R, Murta EF, Michelin MA Barbaresco AA, Adad SJ, de Oliveira AM, Rassi AB and Oton GJ: Human papillomavirus types 16 and 18 and the prognosis of patients with stage I cervical cancer. Clinics (Sao Paulo) 68: 809-814, 2013.

17. El-Akawi ZJ, Al-Hindawi FK and Bashir NA: Alpha-1 antitrypsin (alpha1-AT) plasma levels in lung, prostate and breas cancer patients. Neuro Endocrinol Lett 29: 482-484, 2008.

18. Yamaguchi N, Yamamura Y, Koyama K, Ohtsuji E, Imanishi J and Ashihara T: Characterization of new human pancreatic cancer cell lines which propagate in a protein-free chemically defined medium. Cancer Res 50: 7008-7014, 1990

19. Lee HB, Yoo OJ, Ham JS and Lee MH: Serum $\alpha 1$-antitrypsin in patients with hepatocellular carcinoma. Clin Chim Acta 206 225-230, 1992

20. Pérez-Holanda S, Blanco I, Menéndez M and Rodrigo L: Serum concentration of alpha-1 antitrypsin is significantly higher in colorectal cancer patients than in healthy controls. BMC Cancer 14: 355, 2014.

21. El-Akawi ZJ, Abu-Awad AM, Sharara AM and Khader YS: The importance of alpha-1 antitrypsin ( $\alpha 1-\mathrm{AT})$ and neopterin serum levels in the evaluation of nonsmall cell lung and prostate cancer patients. Neuro Endocrinol Lett 31: 113-116, 2010.

22. Thompson DK, Haddow JE, Smith DE and Ritchie RF: Elevated serum acute phase protein levels as predictors of disseminated breast cancer. Cancer 51: 2100-2104, 1983.
23. El-Akawi ZJ, Abu-Awad AM and Khouri NA: Alpha-1 antitrypsin blood levels as indicator for the efficacy of cancer treatment. World J Oncol 4: 83-86, 2013.

24. Nilsson R, Jain M, Madhusudhan N, Sheppard NG, Strittmatter L, Kampf C, Huang J, Asplund A and Mootha VK: Metabolic enzyme expression highlights a key role for MTHFD2 and the mitochondrial folate pathway in cancer. Nat Commun 5: 3128 , 2014.

25. Ding J, Kuo ML, Su L, Xue L, Luh F, Zhang H, Wang J, Lin TG, Zhang K, Chu P, et al: Human mitochondrial pyrroline-5-carboxylate reductase 1 promotes invasiveness and impacts survival in breast cancers. Carcinogenesis 38: 519-531, 2017.

26. Ou R, Zhang X, Cai J, Shao X, Lv M, Qiu W, Xuan X, Liu J, $\mathrm{Li} \mathrm{Z}$ and Xu Y: Downregulation of pyrroline-5-carboxylate reductase-2 induces the autophagy of melanoma cells via AMPK/mTOR pathway. Tumor Biol 37: 6485-6491, 2016

27. Liu W, Hancock CN, Fischer JW, Harman M and Phang JM: Proline biosynthesis augments tumor cell growth and aerobic glycolysis: Involvement of pyridine nucleotides. Sci Rep 5: 17206 , 2015.

28. De Ingeniis J, Ratnikov B, Richardson AD, Scott DA, Aza-Blanc P, De SK, Kazanov M, Pellecchia M, Ronai Z, Osterman AL and Smith JW: Functional specialization in proline biosynthesis of melanoma. PLoS One 7: e45190, 2012

29. Liu W, Le A, Hancock C, Lane AN, Dang CV, Fan TW and Phang JM: Reprogramming of proline and glutamine metabolism contributes to the proliferative and metabolic responses regulated by oncogenic transcription factor c-MYC. Proc Nat Acad Sci 109: 8983-8988, 2012.

30. Liu L, Liu J, Dai S, Wang X, Wu S, Wang J, Huang L, Xiao X and He D: Reduced transthyretin expression in sera of lung cancer. Cancer Sci 98: 1617-1624, 2007.

31. Wang D, Liang H, Mao X, Liu W, Li M and Qiu S: Changes of transthyretin and clusterin after androgen ablation therapy and correlation with prostate cancer malignancy. Transl Oncol 5: 124-129, 2012.

32. Shimura T, Shibata M, Gonda K, Okayama H, Saito M, Momma T, Ohki S and Kono K: Serum transthyretin level is associated with prognosis of patients with gastric cancer. J Surg Res 227: 145-150, 2018

33. Lorkova L, Pospisilova J, Lacheta J, Leahomschi S, Zivny J, Cibula D, Zivny J and Petrak J: Decreased concentrations of retinol-binding protein 4 in sera of epithelial ovarian cancer patients: A potential biomarker identified by proteomics. Oncol Rep 27: 318-324, 2012.

34. Ehmann M, Felix K, Hartmann D, Schnölzer M, Nees M, Vorderwülbecke S, Bogumil R, Büchler MW and Friess H: Identification of potential markers for the detection of pancreatic cancer through comparative serum protein expression profiling. Pancreas 34: 205-214, 2007.

35. Liu L, Wang J, Liu B, Dai S, Wang X, Chen J, Huang L, Xiao X and He D: Serum levels of variants of transthyretin downregulation in cholangiocarcinoma. J Cell Biochem 104: 745-755, 2008.

36. Fatima I, Sadaf S, Musharraf SG, Hashmi N and Akhtar MW: CD5 molecule-like and transthyretin as putative biomarkers of chronic myeloid leukemia-an insight from the proteomic analysis of human plasma. Sci Rep 7: 40943, 2017.

37. Mählck CG and Grankvist K: Plasma prealbumin in women with epithelial ovarian carcinoma. Gynecol Obstet Invest 37: 135-140, 1994.

38. Bhattacharyya T, Nicholls SJ, Topol EJ, Zhang R, Yang X, Schmitt D, Fu X, Shao M, Brennan DM, Ellis SG, et al: Relationship of paraoxonase 1 (PON1) gene polymorphisms and functional activity with systemic oxidative stress and cardiovascular risk. JAMA 299: 1265-1276, 2008

39. Cockerill GW, Rye KA, Gamble JR, Vadas MA and Barter PJ: High-density lipoproteins inhibit cytokine-induced expression of endothelial cell adhesion molecules. Arterioscler Thromb Vasc Biol 15: 1987-1994, 1995

40. De Souza JA, Vindis C, Nègre-Salvayre A, Rye KA, Couturier M, Therond P, Chantepie S, Salvayre R, Chapman MJ and Kontush A: Small, dense HDL 3 particles attenuate apoptosis in endothelial cells: Pivotal role of apolipoprotein A-I. J Cell Mol Med 14: 608-620, 2010

41. Su F, Kozak KR, Imaizumi S, Gao F, Amneus MW, Grijalva V, $\mathrm{Ng} \mathrm{C}$, Wagner A, Hough G, Farias-Eisner G, et al: Apolipoprotein AI (apoA-I) and apoA-I mimetic peptides inhibit tumor development in a mouse model of ovarian cancer. Proc Natl Acad Sci 107: 19997-20002, 2010. 
42. Zamanian-Daryoush M, Lindner D, Tallant TC, Wang Z, Buffa J, Klipfell E, Parker Y, Hatala D, Parsons-Wingerter P, Rayman $\mathrm{P}$, et al: The cardioprotective protein apolipoprotein A1 promotes potent anti-tumorigenic effects. J Biol Chem 288: 21237-21252, 2013.

43. Zamanian-Daryoush $\mathrm{M}$ and DiDonato JA: Apolipoprotein AI and cancer. Front Pharmacol 6: 265, 2015.

44. Kozak KR, Su F, Whitelegge JP, Faull K, Reddy S and Farias-Eisner R: Characterization of serum biomarkers for detection of early-stage ovarian cancer. Proteomics 5: 4589-4596, 2005

45. Takaishi S and Wang TC: Gene expression profiling in a mouse model of Helicobacter-induced gastric cancer. Cancer Sci 98: 284-293, 2007.

46. Hamrita B, Ben Nasr H, Gabbouj S, Bouaouina N, Chouchane L and Chahed K: Apolipoprotein A1 -75 G/A and $+83 \mathrm{C} / \mathrm{T}$ polymorphisms: Susceptibility and prognostic implications in breast cancer. Mol Biol Rep 38: 1637-1643, 2011.

47. Yamamoto $\mathrm{N}$ and Homma S: Vitamin D3 binding protein (group-specific component) is a precursor for the macrophage-activating signal factor from lysophosphatidylcholine-treated lymphocytes. Proc Natl Acad Sci 88: 8539-8543, 1991.

48. Binder R, Kress A, Kan G, Herrmann K and Kirschfink M: Neutrophil priming by cytokines and vitamin $\mathrm{D}$ binding protein (Gc-globulin): Impact on C5a-mediated chemotaxis, degranulation and respiratory burst. Mol Immunol 36: 885-892, 1999.

49. Zhang HT, Tian EB, Chen YL, Deng HT and Wang QT: Proteomic analysis for finding serum pathogenic factors and potential biomarkers in multiple myeloma. Chin Med J 128 : 1108-1113, 2015.

50. Layne TM, Weinstein SJ, Graubard BI, Ma X, Mayne ST and Albanes D: Serum 25-hydroxyvitamin D, vitamin D binding protein, and prostate cancer risk in black men. Cancer 123 2698-2704, 2017.
51. Mondul AM, Weinstein SJ, Moy KA, Männistö S and Albanes D: Vitamin D-binding protein, circulating vitamin $D$ and risk of renal cell carcinoma. Int J Cancer 134: 2699-2706, 2014.

52. Anic GM, Weinstein SJ, Mondul AM, Männistö S and Albanes D Serum vitamin D, vitamin D binding protein, and risk of colorectal cancer. PLoS One 9: e102966, 2014.

53. Mondul AM, Weinstein SJ, Virtamo J and Albanes D: Influence of vitamin $\mathrm{D}$ binding protein on the association between circulating vitamin D and risk of bladder cancer. Br J Cancer 107 1589-1594, 2012

54. Laszlo GS, Alonzo TA, Gudgeon CJ, Harrington KH, Gerbing RB, Wang YC, Ries RE, Raimondi SC, Hirsch BA, Gamis AS, et al: Multimerin-1 (MMRN1) as novel adverse marker in pediatric acute myeloid leukemia: A Report from the Children's Oncology Group. Clin Cancer Res 21: 3187-3195, 2015.

55. Human Protein Atlas. https://www.proteinatlas.org/ ENSG00000138722-MMRN1/pathology/stomach+cancer. Accessed February 6, 2020

56. Human Protein Atlas. https://www.proteinatlas.org/ ENSG00000138722-MMRN1/pathology/renal+cancer. Accessed February 6, 2020.

57. Chokchaichamnankit D, Watcharatanyatip K, Subhasitanont $P$, Weeraphan C, Keeratichamroen S, Sritana N, Kantathavorn N, Diskul-Na-Ayudthaya P, Saharat K, Chantaraamporn J, et al: Urinary biomarkers for the diagnosis of cervical cancer by quantitative label-free mass spectrometry analysis. Oncol Lett 17: 5453-5468, 2019.

(i) $\Theta$ This work is licensed under a Creative Common Attribution-NonCommercial-NoDerivatives 4.0 International (CC BY-NC-ND 4.0) License. 